\title{
Immunoelectrophoretic Analysis of Cytoplasmic Proteins of Neurospora crassa
}

\author{
By C. A. WILLIAMS AND E. L. TATUM \\ Laboratory of Biochemical Genetics, The Rockefeller University, \\ Nerw York, N.Y., 10021, U.S.A.
}

(Received 9 November 1965)

\begin{abstract}
SUMMARY
Immunoelectrophoretic analysis (IEA) of cytoplasmic proteins of Neurospora crassa revealed more than 30 antigenic components in detectable concentrations in crude extracts. The IEA patterns varied somewhat with culture conditions and age, and with strain. A one-gene polymorphism was recognized but was not associated with any known biochemical or morphological mutant character. Comparison of the IEA patterns given by proteins of several species of fungi with antisera against $N$. crassa revealed the prominent phyletic affinities among the protein antigens within the class Ascomycetes. The results are discussed with emphasis on the methods and the interpretation of immunoelectrophoretic variability.
\end{abstract}

\section{INTRODUCTION}

There are indications that immunochemical techniques when judiciously applied will prove as useful in neurospora research as they have in the study of other micro-organisms. The object of this report is to illustrate the application of immunoelectrophoretic analysis (IEA) to a variety of problems which may arise during an investigation of the proteins of any micro-organism. The experiments are presented as procedures, rather than with intent to report completed investigations. Nearly all of them have been made in conjunction with other techniques during the conduct of continuing research projects.

The main current uses of IEA in neurospora research are: (1) to enumerate the minimal number of antigenic protein components with which one has to contend; (2) to monitor the purification of protein components; (3) to detect qualitative and gross quantitative variations due to known genetic differences; (4) to evaluate effects of different culture conditions; (5) to detect unsuspected genetic polymorphisms among otherwise comparable strains. The application of IEA (or any qualitative immunochemical technique) to one of the last three mentioned purposes must obviously consider the other two as possible causes of any observed differences. Additional considerations of importance to the interpretation of IEA patterns of intracellular antigens are the relative effectiveness of extraction procedures for different strains, different cells and different proteins, and the relative stability of extracted components under subsequent experimental or storage conditions. Solutions of cytoplasmic proteins, and especially crude extracts, are not as stable as blood serum for example, where IEA has been applied with notable success for many of the objectives listed above. 
We have reported several preliminary observations on the variability of IEA patterns among morphological mutants of Neurospora crassa, and a comparative study with certain other species of ascomycetes (Williams \& Tatum, 1961). More species have been examined in an effort to determine some of the phyletic affinities of neurospora. Selected results are shown in the present survey. Other demonstrations are: (1) examples of specific identification procedures applicable to protein components; (2) the effect on the IEA pattern of curtailing a nutritional requirement in the medium; (3) the detection and verification of a one-gene polymorphism not associated with any known biochemical or morphological mutant character.

\section{METHODS}

Organisms. Wild-type Neurospora crassa, sYR 17-3 $A$, and the various biochemical and morphological mutants used are maintained in the collection of this laboratory. Mutants B 28 and B 132 were originally obtained from Dr V.W. Woodward, then of Brookhaven National Laboratory. The slime mutant was kindly supplied by Dr S. Emerson of the California Institute of Technology.

Triangularia, pleurage, and neocosmospora species were obtained from Dr A. Hervey of the New York Botanical Garden. Sordaria and gelasinospora species were furnished by Dr L. S. Olive of Columbia University. Neurospora tetrasperma and N. sitophila, Penicillium uticae and Saccharomyces cerevisae were from the collection in this laboratory.

Culture methods. Unless otherwise stated, mycelial growth was obtained in liquid medium at $30^{\circ}$ in $15 \mathrm{l}$. aerated carboys. Conidial suspensions from 5- to 7-day old slopes were used for inoculation. Glycerol sucrose complete (GSC) medium of Vogel (1956) was generally used except for special purposes mentioned in text. Mycelium mass was collected on a $25 \mathrm{~cm}$. Büchner funnel, washed with distilled water, lyophilized, pulverized, weighed and stored at $5^{\circ}$.

Crosses were made by standard procedures on the chemically defined crossing medium of Westergaard \& Mitchell (1947). Progeny are designated by the strain number of parents (e.g. 37041), the cross-number in a series e.g. (1, 2, 3, etc.), and the ascus number and ascospore number in parentheses. A sample designation would be 37401-2(1-8).

Extraction procedures. Dry pulverized mycelium was ground to a fine powder in a cold mortar. Extractant, 5 parts (w/w) for IEA, was added gradually with continued grinding until the homogeneous paste could be transferred to centrifuge tubes, one part of extractant being retained to flush the mortar into the tube. Extraction mixtures were centrifuged for $90 \mathrm{~min}$. at about $90,000 \mathrm{~g}$ in the Spinco SW 39 swinging-bucket rotor. The clear supernatant fluid was pipetted off for analysis. The protein content of such extracts ranged from 30 to $40 \mathrm{mg}$. $/ \mathrm{ml}$. by biuret assay with a serum albumin standard. The extractant used was generally the same solution as that used in electrophoresis, although this was not essential.

To obtain immunizing antigens the same general procedure was followed, using 10 parts $(\mathrm{w} / \mathrm{w})$ of $0.1 \mathrm{M}-\mathrm{NaCl}$ in $0.05 \mathrm{M}$-sodium phosphate buffer $(\mathrm{pH} \mathrm{7.2})$ as the extractant. The extraction mixture was centrifuged at 15,000 to $18,000 \mathrm{~g}$ and the uncleared supernatant fluid was used as such in immunization procedures.

Immunization and antisera. Strains SYR 17-3 $A$ (wild) and 37401-1(6-3) a, inos 
were the Neurospora crassa strains used for the preparation of antigens for the immunization of two separate groups of rabbits. The antigen suspension was emulsified into an equal volume of Freund's complete adjuvant (Difco) and $2 \mathrm{ml}$. were divided among several injection sites. Subsequent injections were given intravenously in series of three increasing doses with intervals of one day. Antisera were tested one week after the end of each series, and bulk bleedings $(25 \mathrm{ml}$.) began when IEA patterns from individual animals were sufficiently complex. Pools were made of bleedings which gave similar patterns. Special pools were blended from these for specific purposes.

Immunoelectrophoretic analysis (IEA). The microtechnique on $25 \times 75 \mathrm{~mm}$. glass slides was used. Other conditions were as originally described by Grabar \& Williams (1955): electrophoresis at room temperature for $90 \mathrm{~min}$. at $5 \mathrm{~V} / \mathrm{cm}$. in veronal buffer, ionic strength $0 \cdot 038, \mathrm{pH} 8 \cdot 2$. Development of patterns by diffusion of antiserum continued up to $40 \mathrm{hr}$ at $5^{\circ}$. Slides were washed, dried, and stained with bromphenol blue. Patterns were analysed on photographic enlargements obtained by using the slides as negative plates.

Identification of specific proteins. Catalase and the 'non-specific' carboxylic esterases were identified according to the methods of Uriel (1960), catalase by immersion of the dry slides for a few seconds in $3 \% \mathrm{H}_{2} \mathrm{O}_{2}$, esterase by $\beta$-naphthylacetate solution followed by diazo blue $\mathrm{B}$ as coupling agent. Alkaline phosphatase was detected by immersion in a solution of naphthol AS MX phosphate followed by diazo blue B. Glucose-6-phosphate dehydrogenase detection was done by an adaptation of a histochemical method which used the substrate, TPN, $\mathrm{KCN}, \mathrm{MgCl}_{\mathbf{2}}$, and 2 ( $p$-iodophenyl)-3( $p$-nitrophenyl)-5-phenyl tetrazolium chloride (Nutritional Biochemicals Corp.).

\section{RESULTS}

\section{Enumeration of antigenic components}

Every antiserum develops an IEA pattern which is in some way unique. It is not possible, therefore, to establish a single basic pattern. The most to expect is that a pattern may be recognized as more or less typical and complete with respect to the components of interest and to components which serve as mobility standards. Plate 1, fig. 1A, illustrates a pattern of Neurospora crassa strain 37401-1(6-3) a, inos. Electrophoresis was done with $60 \mu \mathrm{g}$. extract protein, and the pattern was developed by antiserum pool N-II concentrated 10 times. On the original photograph 22 reaction lines were clearly distinguishable. In addition, there are several other components which are known to be precipitated, most likely in extreme antibody excess. The antibody excess reaction is one of diffuse, often faint precipitation. It is likely that several such reactions comprise the hazy background in the region to the left of the starting well. Two arcs, SS and RS are rather constant features of IEA patterns of Neurospora crassa extracts, and are used as mobility standards. The slow standard component (SS) is isoelectric around $\mathrm{pH} \mathrm{8.2,} \mathrm{and} \mathrm{the} \mathrm{rapid}$ standard component (RS) migrates approximately like serum albumin.

\section{Identification of precipitates}

Before staining with bromphenol blue, the slide shown in Pl. 1, fig. 1, A was immersed in $3 \% \mathrm{H}_{2} \mathrm{O}_{2}$ for 5 sec., then washed thoroughly in water. Catalase, which is 
active even when precipitated by specific antibody, breaks down $\mathrm{H}_{2} \mathrm{O}_{2}$ and produces bubbles of $\mathrm{O}_{2}$ in the pattern. The short line locates the catalase precipitate. Without the $\mathrm{H}_{2} \mathrm{O}_{2}$ treatment it was sometimes impossible to distinguish this precipitate from the hazy background.

Many enzymes can be detected in this manner; as yet none of the more prominent ares in the pattern has been identified as that of a specific enzyme. The enzyme precipitates detected thus far (such as the alkaline phosphatase, Pl. 1, fig. 1 B) or the various non-specific esterases (Pl. 1, fig. $1 \mathrm{D}, \mathrm{E})$ are typical of an antibody excess reaction suggesting very small quantities of the antigenic protein. The glucose-6-phosphate dehydrogenase precipitate (Pl. 1, fig. $1 \mathrm{C}$ ) was not in extreme antibody excess but there was not sufficient protein in the antigen-antibody complex to give visible staining with bromphenol blue.

Except for D, in Pl. 1, fig. 1, the total IEA protein patterns would be the same as Pl. 1, fig. $1 \mathrm{~A}$, since the same extract was used for all. Pl.1, fig. $1 \mathrm{D}$ was produced with an extract of the slime mutant of Neurospora crassa, a strain devoid of organized cellwall. In addition to having several other mutant genes (arg, ad-2, nic-1, lys-3, aur, $c r, o s)$, slime seemed deficient for 2 of 4 esterases. The slime pattern may be compared with a wild-type pattern in Pl. 2, fig. 4. These patterns were obtained by shorter development times, hence are not as complex as that of Pl. 1, fig. $1 \mathrm{~A}$.

\section{Pattern variation}

We reported previously (1961) that the IEA pattern and the total protein distribution by moving boundary electrophoresis vary with the age of the culture. Between 1 and 5 days of growth in liquid medium there is a marked increase in the relative amounts of certain of the more rapidly migrating components in the region of the rapid standard-mobility component RS. This observation was confirmed with strains other than the wild type, particularly with two morphological mutants of Neurospora crassa. One of these (R 1006) is a temperature-sensitive strain, growing as a colonial at $30^{\circ}$ but with almost normal morphology at $25^{\circ}$. In addition to showing variability with respect to age, there were also differences in the IEA patterns of cultures of similar age grown at the two different temperatures. Since the change of temperature also produced a change of morphology, it was of interest to compare the patterns obtained with a non-facultative morphological mutant and with the the wild strain. There appeared to be no correlation of the pattern modifications with colonial morphology as such. Since some mutant strains of $\boldsymbol{N}$. crassa grow more rapidly than others, and since any one strain may grow at different rates according to the temperature, the chronological age of a culture was not thought to be a suitable basis for comparison of strains with one another. Comparable dry weight of mycelium/given volume of medium during rapid growth was used as a better approximation of physiological age. Patterns also vary depending upon the method of preparing 'comparable' extracts for analysis. Extractable protein/ unit dry weight mycelium varies with age and also from strain to strain. Extracts may be adjusted to equal total protein or compared on the basis of equivalent solvent: mycelium = dry-weight ratio. Any approach must find its rationale in experimental results, since there is no way of being certain what proportion of the total extractable protein contributes to the readily observed IEA pattern, or how this proportion may vary with strain or with age of a culture. There is at least one 
report that protein synthesis in Neurospora continues even after the increase of mycelial mass ceases (Ballantine \& Stephens, 1951).

IEA patterns do not vary markedly with different extracting solutions. Veronal buffer $(0.038 \mathrm{M}, \mathrm{pH} 8.2)$, phosphate buffer $(0.05 \mathrm{M}, \mathrm{pH} 7 \cdot 6)$ or distilled water give similar patterns when the extract is fresh. On standing at $5^{\circ}$, or after freezing and thawing, however, there are differences apparently related to differential stability of some components in the different solvents. With some strains or cultures there is copious spontaneous precipitation of extracted material on standing or after freezing and thawing, irrespective of the extracting solvent. This material does not seem to comprise much of the protein which contributes the major components of the IEA pattern. Reconstituted ammonium sulphate precipitates are somewhat more stable in solution, but at $70 \%$ saturation a considerable number of the proteins which constitute the total pattern remain in the supernatant fluid. Dialysis against 4.8 or $5 \mathrm{M}-\left(\mathrm{NH}_{4}\right)_{2} \mathrm{SO}_{4}$ yields a precipitate which when reconstituted gives a pattern similar to that of the fresh crude extracts.

\section{Variability with nutritional deprivation}

Biochemical mutants of Neurospora crassa which require methionine (4984, $m e-7)$, arginine (27497, arg-5), or inositol (17401, inos), respectively, were grown in media containing decreasing amounts of the nutritional requirement, from the optimal concentration to that at which growth was possible but severely limited. Cultures were incubated for 3 days in $500 \mathrm{ml}$. medium on a rotary shaker. All inocula consisted of $30 \times 10^{6}$ washed conidia in minimal medium. Mycelia were harvested, lyophilized, and weighed in the usual fashion. Extracts were prepared with $10 \mathrm{ml}$. veronal buffer/g. mycelium. Extractable protein/unit dry wt. mycelium was about the same for all extracts of the arg and me mutants, but decreased progressively with lower concentrations of inositol in the medium in the case of the inos mutant. When the extracts were compared by IEA at equal protein concentrations, modifications in the patterns were most marked for the me mutant and slight for the arg and inos mutants. The comparative patterns of extracts of the me mutant developed with antiserum pool N-VI-A are shown in Pl. 1, fig. 2. They represent cultures grown: (A) with optimal methionine concentration $(40 \mu \mathrm{g} . / \mathrm{ml}$.); (B) with suboptimal concentration $(20 \mu \mathrm{g} . / \mathrm{ml}$.) which did not impair growth in 3 days; (C) with minimal concentration $(5 \mu \mathrm{g} . / \mathrm{ml}$.) at which growth was severely limited. Those antigenic components which are modified noticeably in relative concentration are marked with short vertical lines.

\section{Genetic polymorphism}

The component labelled VMP (variable mobility protein) in Pl. 1, fig. 1 A first attracted attention because in the patterns of most of strains examined, whether wild or mutant, this arc indicated that the component migrated more slowly than the rapid standard mobility component (RS). The F (fast) character appeared in two of eight strains derived from a single cross made for other purposes. A fast variant of mating type $a$ was crossed with a slow strain of mating type $A$ to determine the mode of inheritance of the mobility variation of the protein. Ten asci were isolated and the 8 ascospores numbered sequentially. Each ascospore was cultured and tested for inositol requirement and mating type. Two-day cultures in $300 \mathrm{ml}$. complete medium were 
harvested in the usual way, giving yields of 0.7 to $\mathbf{0 . 9} \mathrm{g}$. dry wt. mycelium. Extracts were adjusted to equal protein concentration and examined by IEA. A special antiserum pool $(\mathrm{N}-\mathrm{V})$ was blended from three individual rabbit antisera and concentrated ten-fold. It contained antibody against VMP but did not develop prominent arcs for other components with which it might be confused. Plate 2, fig. 3, shows the patterns of the parents, Neurospora crassa 37401-1(6-3) $a$ and 1(5-3) $A$, along with those of the even numbered isolates (one member of each pair) from the first ascus. VMP is marked on each pattern and mating types are indicated. It is seen that $F$ VMP occurs in 2(1-2) $a$ and 2(1-8) $A$ in a segration pattern typical of a single-gene character.

Table 1. Neurospora crassa: segregation of VMP characters in backcross progenies

\begin{tabular}{|c|c|c|c|c|}
\hline \multirow[b]{2}{*}{$\begin{array}{c}\text { Back-cross } \\
\text { No. }\end{array}$} & \multirow[b]{2}{*}{ Cross* } & \multicolumn{3}{|c|}{ Analysis of progeny } \\
\hline & & $\begin{array}{c}\text { Ascospore } \\
\text { no. }\end{array}$ & $\begin{array}{l}\text { Mating } \\
\text { type }\end{array}$ & $\begin{array}{l}\text { VMP } \\
\text { type }\end{array}$ \\
\hline \multirow[t]{4}{*}{1} & $2(1-1) a \times 1(5-3) A$ & 1 & $\mathbf{a}$ & $\mathbf{F}$ \\
\hline & & $\mathbf{3}$ & a & $\mathbf{f}$ \\
\hline & \multirow[t]{2}{*}{$\mathbf{F}$} & $\mathbf{5}$ & A & $\mathbf{f}$ \\
\hline & & 7 & $\mathbf{A}$ & $\mathbf{F}$ \\
\hline \multirow[t]{4}{*}{2} & $2(1-2) a \times 1(5-3) A$ & 1 & $\mathbf{A}$ & $\mathbf{f}$ \\
\hline & \multirow{3}{*}{$\mathbf{F}$} & $\mathbf{3}$ & $\mathbf{A}$ & $\mathbf{f}$ \\
\hline & & $\mathbf{5}$ & a & $\mathbf{F}$ \\
\hline & & 7 & a & - \\
\hline \multirow[t]{4}{*}{3} & $2(1-3) A \times 1(6-3) a$ & 1 & $\mathbf{A}$ & $\mathbf{F}$ \\
\hline & \multirow{3}{*}{$\mathbf{f}$} & 3 & A & F \\
\hline & & 5 & $\mathbf{a}$ & $\mathbf{f}$ \\
\hline & & 7 & $\mathbf{a}$ & $\mathbf{f}$ \\
\hline \multirow[t]{4}{*}{4} & $2(1-4) A \times 1(6-3) a$ & 1 & $\mathbf{a}$ & (f) \\
\hline & \multirow{3}{*}{$\mathbf{f}$} & $\mathbf{3}$ & a & (f) \\
\hline & & 5 & $\mathbf{A}$ & $\mathbf{F}$ \\
\hline & & 7 & A & $\mathbf{F}$ \\
\hline \multirow[t]{4}{*}{5} & \multirow{2}{*}{$2(1-5) a \times 1(5-3) A$} & 1 & a & (f) \\
\hline & & 3 & a & (f) \\
\hline & \multirow[t]{2}{*}{$\mathbf{f}$} & $\mathbf{5}$ & A & (f) \\
\hline & & 7 & $\mathbf{A}$ & (f) \\
\hline \multirow[t]{4}{*}{6} & \multirow[t]{2}{*}{$2(1-6) a \times 1(5-3) A$} & 1 & $\mathbf{A}$ & $(-)$ \\
\hline & & $\mathbf{3}$ & A & (f) \\
\hline & \multirow[t]{2}{*}{$\mathbf{f}$} & 5 & $\mathbf{a}$ & (f) \\
\hline & & 7 & $\mathbf{a}$ & (f) \\
\hline \multirow[t]{4}{*}{7} & \multirow[t]{2}{*}{$2(1-7) A \times 1(6-3) a$} & $\mathbf{1}$ & $\mathbf{a}$ & $\mathbf{F}$ \\
\hline & & $\mathbf{3}$ & $\mathbf{a}$ & $\mathbf{F}$ \\
\hline & \multirow[t]{2}{*}{$\mathbf{F}$} & $\mathbf{5}$ & A & $\mathbf{F}$ \\
\hline & & 7 & $\mathbf{A}$ & $\mathbf{F}$ \\
\hline \multirow[t]{4}{*}{8} & \multirow[t]{2}{*}{$2(1-8) A \times 1(6-3) a$} & 1 & $\mathbf{a}$ & $\mathbf{F}$ \\
\hline & & 3 & a & $\mathbf{F}$ \\
\hline & \multirow[t]{2}{*}{$\mathbf{F}$} & $\mathbf{5}$ & $\mathbf{A}$ & $\mathbf{F}$ \\
\hline & & 7 & $\mathbf{A}$ & $\mathbf{F}$ \\
\hline
\end{tabular}

* $\mathrm{x}(\mathrm{y}-\mathrm{z}): x$, cross no. in a series; $y$, ascus no. from cross; $z$, ascospore no. in ascus.

$\dagger$ F, fast VMP; f, slow VMP; ( ), one extract only; - , arc unidentifiable.

The homology of the fast and slow VMP was established by immunochemical identity reactions in pattern-interaction slides described by Williams \& Wemyss (1961). The 8 ascospore cultures from ascus 1 were back-crossed to the parent of the 
opposite mating type and an ascus from the progeny of each cross was isolated, tested, cultured and harvested for IEA as before. IEA results with extracts from cultures of odd-numbered ascospores from each backcross, shown in Table 1, are consistent with a single gene difference determining a higher or lower mobility of the VMP.

There was some indication that, in addition to the genetic factor, cultural conditions played a role in the mobility of this protein. The VMP of temperaturesensitive strain Neurospora crassa $\mathbf{R} \mathbf{1 0 0}$ is fast when the culture is grown at $25^{\circ}$ and slow at $30^{\circ}$ when the strain shows colonial morphology. However, B 28 and B 132, other colonials, have a fast and a slow VMP, respectively, at $30^{\circ}$, so it is not a characteristic which is associated with colonial growth or temperature per se. In the 37401 inos strains used for the genetic analysis of VMP there was no noticeable impairment of growth on minimal medium supplemented with $50 \mathrm{mg}$. inositol/l.

\section{Species differences and phyletic affinity}

Several species of ascomycetes were cultivated on complete medium; growth proceeded at widely different rates. Most of these cultures were harvested 2 days after inoculation, but some required up to 7 days to yield sufficient mycelial growth for harvest. Neurospora, gelasinospora neocosmospora and most sordaria species grew quite well, producing between 11 and $21 \mathrm{~g}$. dry wt. $/ 151$. medium in $48 \mathrm{hr}$. Triangularia bambusae, Pleurage anserina, Sordaria fimicola and Penicillium uticae grew poorly, and produced less than $5 \mathrm{~g} . / 15 \mathrm{l}$. in 5 days.

Extracts were compared on the basis of equal protein concentration with two different antiserum pools. Pool N-II prepared with antiserum from five rabbits immunized with Neurospora proteins over a period of 5 months revealed striking differences in the IEA patterns of the various species. Antigenic homologues were detectable, however, in the extracts of such distantly related species as the common yeast Saccharomyces cerevisiae. Pool N-VI-A was one vol. pool N-II and 2 vol. serum from two rabbits which had been immunized for more than 7 months.

Plate 2, fig. 4, illustrates the patterns of three species considered to be fairly near relatives of Neurospora crassa and which grew well on the medium used. The patterns were developed for $\mathbf{2 4} \mathrm{hr}$ with pool $\mathrm{N}-\mathrm{II}$ antiserum. It is evident from the number and intensity of the arcs of specific precipitate that gelasinospora and sordaria species are more distant relatives of $N$. crassa than is $N$. sitophila. When the same extracts were compared by development with pool N-VI-A antiserum, however, the striking differences in number and intensity of the reactions disappeared; such patterns are shown in $\mathrm{Pl}$. 2, fig. 5. It is important for studies of this nature to show that the actual antigenic composition of the extracts from different species are similar, a fact which can be revealed by the less specific antibodies present in pool N-VI-A antiserum. The antibodies of pool N-II, which are more specific for $N$. crassa protein antigens may then be confidently used to assess phylogenetic distance among species.

\section{DISCUSSION}

In spite of the sensitivity, specificity and resolving power of immunoelectrophoretic analysis (IEA), there are the obvious limitations inherent in all immunochemical techniques. First, one is at the mercy of an animal, in our case the rabbit, 
which is unconcerned with the research aims of the investigator. The antibodies produced may be highly specific or rather non-specific, as illustrated by the relative activities of antiserum pools $\mathrm{N}-\mathrm{II}$ and $\mathrm{N}-\mathrm{II}-\mathrm{A}$ reacted with antigens from different species of fungi (see Pl. 2, figs. 4, 5). Also, the amounts of antibodies produced may have no relationship to the relative concentrations of the antigens in the extract to be analysed, as indicated by the significant number of antibody-excess reactions in the IEA patterns. Further, every animal immunized with a mixture of antigens as complex as a protoplasmic extract will produce a different spectrum of specific antibodies in different relative amounts.

All of these variables, however, may prove useful in a given research problem. Individual antisera may be used for their particular qualities or they may be selectively pooled for special applications, as was done for the analysis of the VMP protein and the comparison of the several species of ascomycetes. The fact that significantly more antibody is produced to minor components, such as certain enzymes, relative to their concentration in the extract, makes broad spectrum antisera valuable tools to monitor the purification of these antigens. As their relative concentrations in fractions are increased, their corresponding arcs of precipitate will become sharper, permitting their clear distinction from antigenic impurities. Specific identification tests for enzymes in immune precipitates have been devised for many enzymes (Uriel, 1966). Roberts \& Pateman (1964) reported the use of such techniques in studies of glutamate dehydrogenase of neurospora.

It is now a commonplace that the protein composition, both in quality and quantity, is as characteristic of a species as the gross morphology or the metabolic and biosynthetic pathways. IEA and other immunochemical methods offer the possibility of examining this degree of phenotypic expression in broad but sensitive parameters. In organisms with which environmental as well as genetic manipulation is possible, investigations by IEA might well uncover important new directions for the study of heredity/environment interaction in adaptive processes. No special claim is made in this regard for the VMP component described in these experiments, but proteins with such properties might have special interest. Its identification with some structure or function might provide a means to assess the importance of minor changes in protein structure. The VMP component might also serve as a strain marker among otherwise wild-type cultures.

The analysis of different species has theoretical as well as practical implications. In higher organisms, such as the mammals and specifically the Primates, immunochemical correspondence has been shown to be consistent with accepted systematics and phylogeny (Goodman, 1963; Williams, 1964; Hafleigh \& Williams, 1966). The systematics of micro-organisms are in many cases based on characters that have not been considered in the classification of higher organisms. In addition, phylogenetic relationships, and thus evolutionary processes, can only be surmised because of the lack of any extensive palaeontological evidence. Among systematic or taxonomic relatives of micro-organisms, however, the relative correspondence of macromolecular structures such as the nucleic acids (McCarthy \& Bolton, 1963; Drs S. K. Dutta, W. P. McWhorter and V. W. Woodward, personal communications) and the proteins should reveal phylogenetic relationships. Studies of this sort may distinguish between systematic schemes which reflect true biological affinities and those which are merely convenient. At present only the proteins provide 
material for assessing structural similarities in defined portions of the genomes of different species. Quantitative and qualitative analysis of these similarities, in providing a measure of genetic relatedness, provides also the starting-point for a rational evaluation of evolutionary trends among micro-organisms. Immunochemical analysis of structural correspondence, while not ideal theoretically, does offer the possibility for extensive collection of data which are satisfactory for first approximations of phylogenetic relationships.

This research was supported by a grant (GB 1318) from the National Science Foundation. We wish to thank Dr Laura F. Garnjbost of this laboratory for advice and help with the genetic crosses, and Mr G. Kuzmycz and Miss A. S. Hafleigh for expert technical assistance.

\section{REFERENCES}

Ballentine, R. \& Stephens, D. G. (1951). The biosynthesis of stable cobaltoproteins by plants. $J$. cell and comp. Physiol. 37, 369.

Goodman, M. (1963). Serological analysis of the systematics of recent hominoids. Human Biol. 35, 377.

Grabar, P. \& Williams, C. A. (1955). Méthode immunoélectrophoretique d'analyse de mélanges de substances antigèniques. Biochim. biophys. Acta, 17, 67.

Hafleigh, A. C. \& Williams, C. A. (1966). Antigenic correspondence of serum albumin among the Primates. (In the Press.)

McCarthy, B. J. \& Bolton, E. T. (1963). An approach to the measurement of genetic relatedness among organisms. Proc. natn. Acad.Sci., U.S.A. 50, 156.

Roberts, D. B. \& Pateman, J. A. (1964). Immunological studies of amination deficient strains of Neurospora crassa. J. gen. Microbiol. 34, 295.

UrIEL, J. (1960). Les réactions de characterisation des constituants protéiques. In Analyse Immunoélectrophorétique. Ed. by P. Grabar and P. Burtin, p. 33. Paris: Masson.

UrIEL, J. (1966). Color reactions for the identification of antigen-antibody precipitates in gel-diffusion media. In Methods in Immunology and Immunochemistry. Ed. by M. W. Chase and C. A. Williams. Vol. 2, ch. 14. New York: Academic Press.

VoGel, H. J. (1956). A convenient growth medium for Neurospora. Microbiol. Genet. Bull. 13, 43.

WestergaArd, M. \& Mitchell, H. K. (1947). A synthetic medium favoring sexual reproduction. Am. J. Bot. 34, 573.

Wrlliams, C. A. (1964). Immunochemical analysis of serum proteins of the Primates: a study in molecular evolution. In Evolutionary and Genetic Biology of Primates, Ed. by J. Buettner-Janusch. Vol 2, p. 25. New York: Academic Press.

Williams, C. A. \& TAtum, E. L. (1961). Immunoelectrophoretic analysis of mutant and wild strains of Neurospora. Proc. 5th int. Congr. Biochem., Moscore, p. 405.

Williams, C. A. \& Wemyss, C. T. (1961). Experimental and evolutionary significance of similarities among serum protein antigens of man and the lower Primates. Ann. N.Y. Acad. Sci. 94, 77.

\section{EXPLANATION OF PLATES}

Plate 1

Fig. 1. IEA pattern of Neurospora crassa extracts. A. Total pattern of 37401-1(6-3)a, inos. Slide stained with bromphenol blue after immersion in $3 \% \mathrm{H}_{2} \mathrm{O}_{2}$ to reveal the position of catalase (indicated by short vertical line). The variable mobility protein (VMP) is shown in Fig. 3. RS and SS refer to the rapid and slow standard mobility components, respectively. B. IEA procedure identical to that of $\mathrm{A}$ with staining for alkaline phosphatase (AP) activity. Picture taken before counterstaining with bromphenol blue. C. IEA procedure identical to that of $B$ with staining for glucose-6-phosphate dehydrogenase (G-6-PDH) activity. D. and E. Extract of slime mutant 
(D) and of N. crassa 37401-1(6-3)a, inos (E) compared on same slide for non-specific carboxylic esterases.

Fig. 2. IEA pattern of extracts of methionine-deficient $N$. crassa mutant (4894, me-7) grown on minimal media augmented with methionine $40 \mu \mathrm{g}$., $20 \mu \mathrm{g}$. or $5 \mu \mathrm{g} . / \mathrm{ml}$. Antigenic components which were affected by decreasing the amount of the nutrient are indicated by short vertical lines.

\section{Plate 2}

Fig. 3. IEA patterns showing variable mobility protein (VMP) positions in extracts of cultures of even-numbered ascospores from a single ascus derived from the cross of $N$. crassa strains 1(5-3) A and 1(6-3)a.

Fig. 4. IEA patterns of Neurospora crassa, slime mutant (see Fig. 1D), N. sitophila, a gelasinospora species, and a sordaria species developed with antiserum to $N$. crassa antigens. Note greater similarity of antigens of $N$. sitophila to those of $N$. crassa than to antigens of other genera.

Fig. 5. IEA patterns of same species as shown in Fig. 4 developed with an antiserum pool containing a wide range of specific antibodies. Many more antigenic homologues are revealed in the nonneurospora species by this antiserum than the more specific pool used to obtain the patterns in fig. 4 . 
Journal of General Microbiology, Vol. 44, No. 1

Plate 1

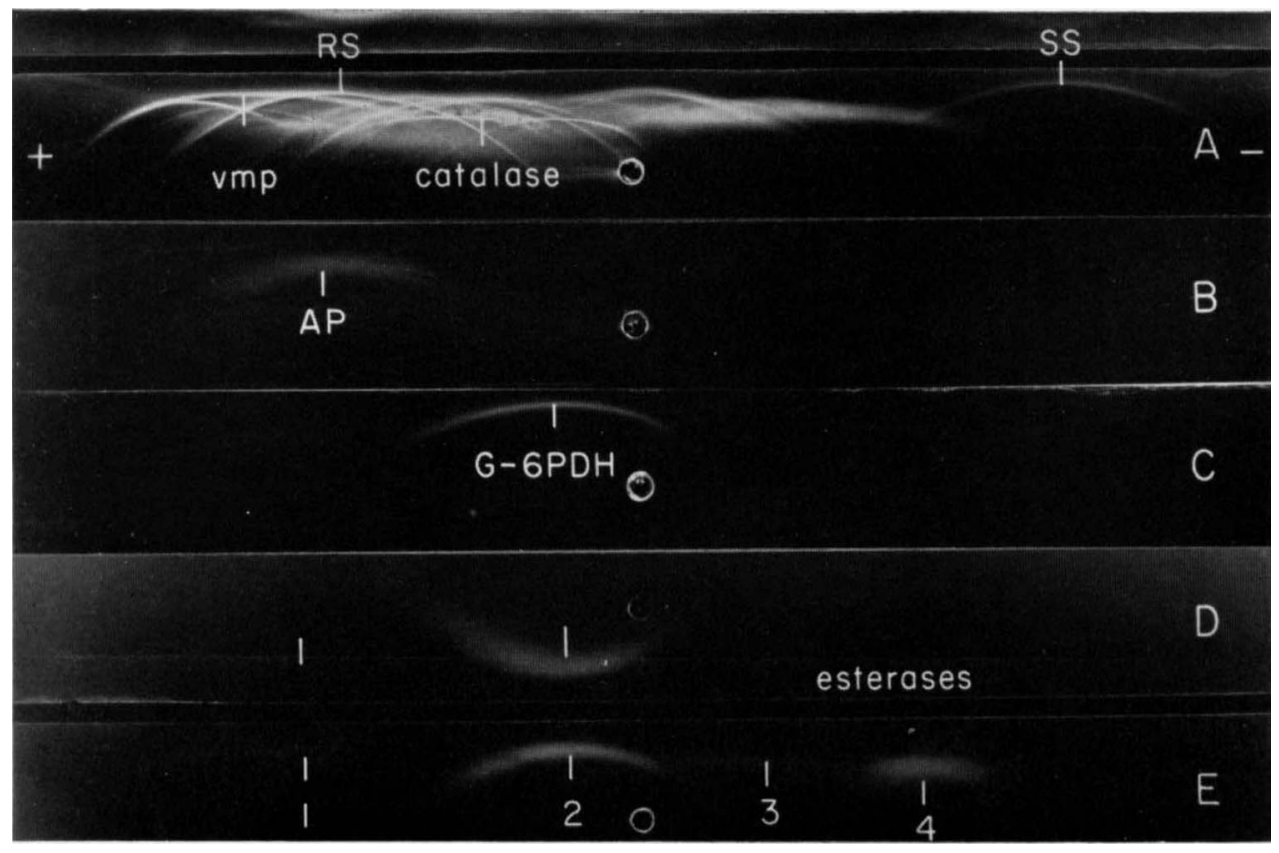

Fig. 1



Fig. 2 

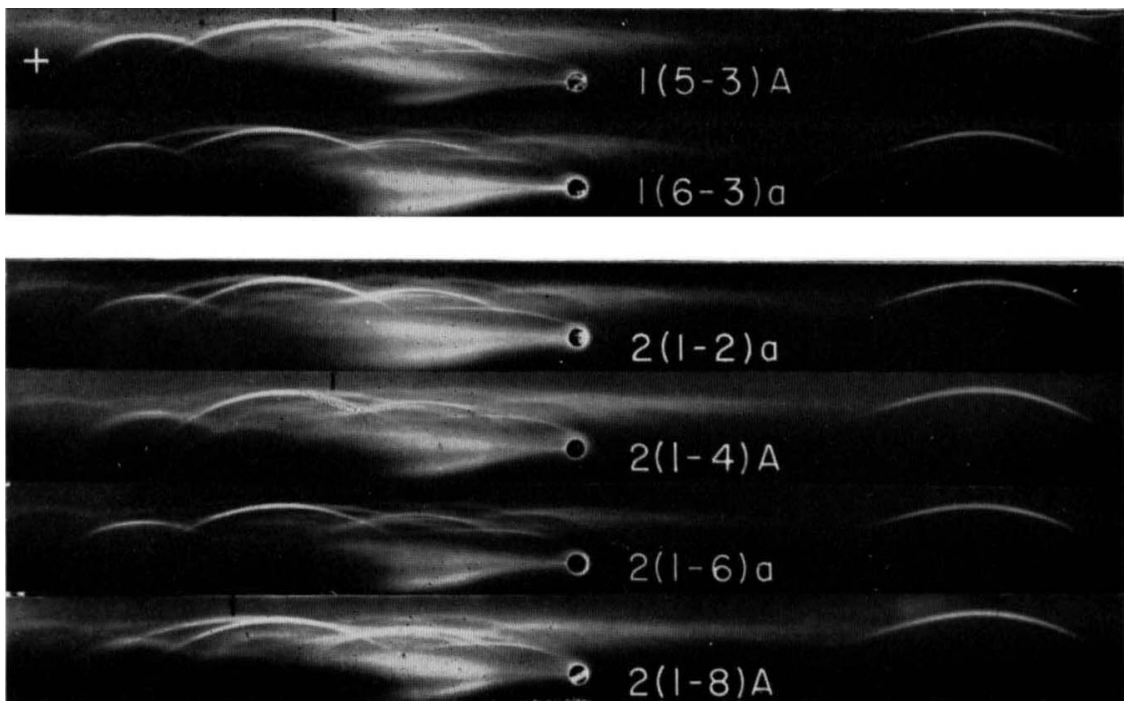

Fig. 3

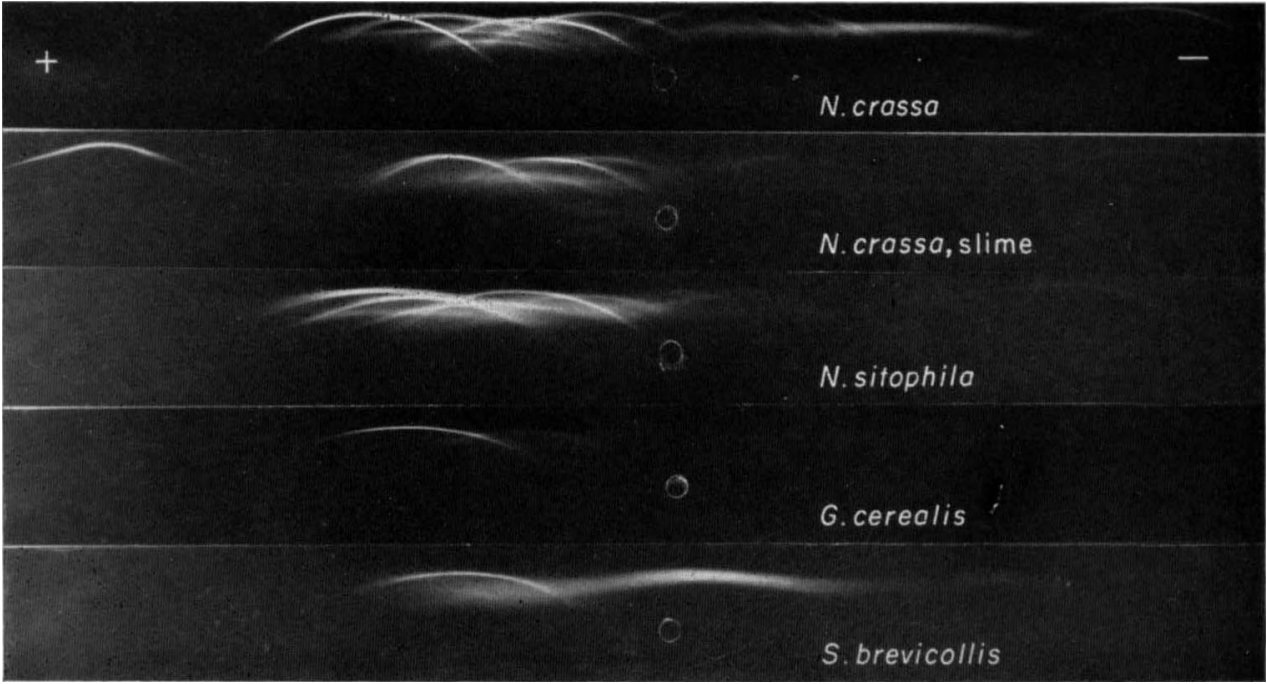

Fig. 4

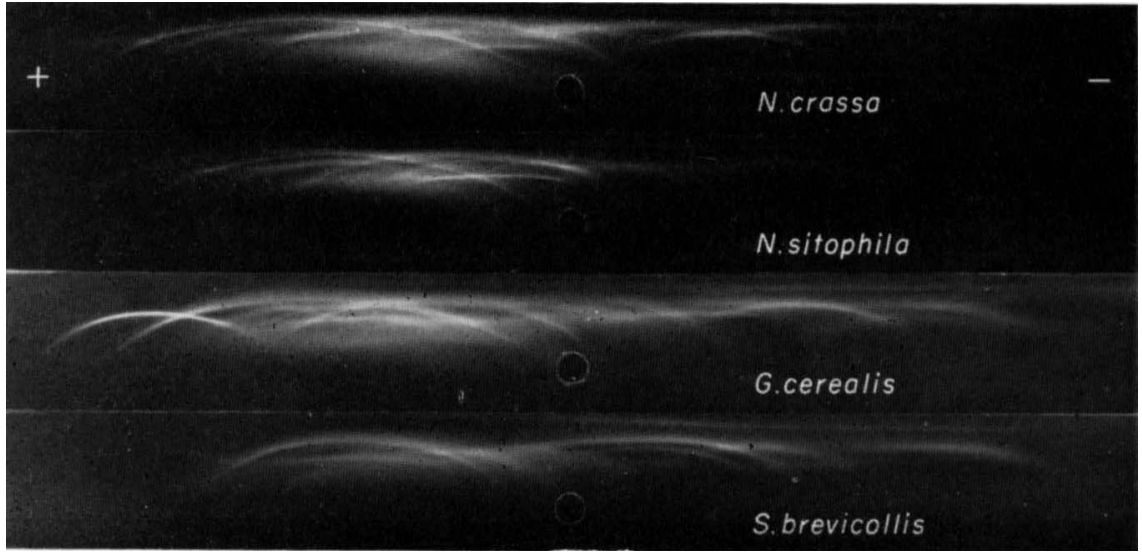

Fig. 5

C. A. WILliams and E. L. TATUM 